\title{
(C) OPEN ACCESS \\ Validity of inducible ischaemia as a surrogate for adverse outcomes in stable coronary artery disease
}

\author{
Adam Timmis, ${ }^{1,2}$ Antony Raharja, ${ }^{1}$ R Andrew Archbold ${ }^{2}$ Anthony Mathur ${ }^{1,2}$
}

'Barts and The London School of Medicine and Dentistry, Queen Mary University London, London, UK

${ }^{2}$ Department of Interventional Cardiology, Barts Heart Centre, London, UK

\section{Correspondence to}

Professor Adam Timmis, Barts Heart Centre, London EC1A 7BE, UK; a.d.timmis@qmul. ac.uk

Received 18 March 2018 Revised 25 April 2018 Accepted 17 May 2018 Published Online First 6 June 2018

Check for updates

To cite: Timmis A, Raharja A, Archbold RA, et al. Heart 2018;104:1733-1738.

\section{ABSTRACT}

Regional myocardial ischaemia is commonly expressed as exertional angina in patients with stable coronary artery disease (CAD). It also associates with prognosis, risk tending to increase with the severity of ischaemia. The validity of myocardial ischaemia as a surrogate for adverse clinical outcomes, however, has not been well established. Thus, in cohort studies, ischaemia testing has failed to influence rates of myocardial infarction and coronary death. Moreover, in clinical studies, pharmacological and interventional treatments that are effective in correcting ischaemia have rarely been shown to reduce cardiovascular (CV) risk. This contrasts with statins and other anti-inflammatory drugs that have no direct effect on ischaemia but improve CV outcomes by modifying the atherothrombotic disease process. Despite this, and with little evidence of patient benefit, stress testing is commonly used during the follow-up of patients with stable CAD when the demonstration of ischaemic change may be seen as a target for treatment, independently of symptomatic status. Substitution of a symptom-driven management strategy has the potential to reduce rates of non-invasive stress testing, unnecessary downstream revascularisation procedures and use of valuable resources in patients with stable $\mathrm{CAD}$ without adverse consequences for $\mathrm{CV}$ risk.

\section{INTRODUCTION}

In patients with coronary artery disease (CAD), the burden of ischaemia is related to the extent and functional significance of luminal obstruction, as influenced by lesion characteristics, collateral development and other factors affecting the balance of myocardial oxygen supply and demand. Ischaemia is an important determinant of symptoms, usually expressed as angina in patients with stable CAD, but the relationship is unpredictable, and 'silent' myocardial ischaemia can often be demonstrated in patients with CAD who experience no angina. ${ }^{1}$ Alternatively, angina may occur in patients with angiographically unobstructed coronary arteries. ${ }^{2}$

Detection of ischaemia non-invasively relies on functional cardiac testing during exertional or pharmacological stress. Functional responses to ischaemia are typically regional in distribution and resolve with relief of the stress. They include electrocardiographic ST segment and T wave changes, echocardiographic left ventricular wall motion abnormalities and perfusion defects detected by single-photon emission computed tomography (SPECT) or cardiac magnetic resonance (cMR) perfusion imaging. Alternatively, fractional flow reserve (FFR) may be used to assess the functional significance of coronary stenoses. ${ }^{3}$ FFR is usually measured during invasive coronary angiography, but less invasive methods are now available using analysis of quantitative flow ratio or CT coronary angiography (CTCA). ${ }^{45}$

Inducible ischaemia during stress testing is widely used as a surrogate of cardiovascular (CV) risk in patients with stable CAD and may reduce thresholds for revascularisation in symptomatic and asymptomatic subgroups according to international guideline recommendations. ${ }^{6}{ }^{7}$ Inducible ischaemia has also been used as a surrogate endpoint in clinical outcome trials. ${ }^{8}$ However, its validity as a surrogate of CV risk merits further scrutiny. In this article, we examine whether or not myocardial ischaemia meets the following key criteria for surrogacy of adverse clinical outcomes in patients with stable CAD: (1) an association with major adverse cardiac events, (2) a place on the causal pathway and (3) responsiveness of cardiac events to treatment-related changes in inducible ischaemia. ${ }^{8-10}$

\section{Ischaemia and the risk of major adverse cardiac events}

Cohort studies in patients with known or suspected CAD have reported associations between myocardial ischaemia and major adverse cardiac events. In a 1998 study of 5183 patients undergoing stress SPECT, ${ }^{11}$ the risk of cardiac death or myocardial infarction during follow-up for 2 years was low in patients with normal scans but increased incrementally with worsening scan abnormalities. A 2012 study of stress SPECT confirmed these findings by showing that the risk of acute coronary syndromes during 5-25 years of follow-up of 1287 asymptomatic siblings of people with premature CAD showed a dose-response relationship with the severity of ischaemia. ${ }^{12}$ A 2013 meta-analysis of 19 studies of stress cMR involving a total of 11636 patients followed up for an average of 32 months showed that patients with ischaemia had a higher incidence of myocardial infarction (MI) (OR 7.7; p <0.0001), CV death (OR 7.0; $p<0.0001)$ and the combined endpoint (OR 6.5; $\mathrm{p}<0.0001)$ compared with those with a negative study. ${ }^{13}$

In the prospective 'Heart and Soul' study of 1024 patients undergoing stress echocardiography, inducible ischaemia was an independent predictor of both CV (RR 2.28 (95\% CI 1.44 to 3.61)) and non-CV (RR 1.83 (95\% CI 1.24 to 2.70)) mortality during follow-up for 10 years. ${ }^{14}$ The larger The Prospective Observational Longitudinal Registry of Patients With Stable Coronary Artery Disease (CLARIFY) 

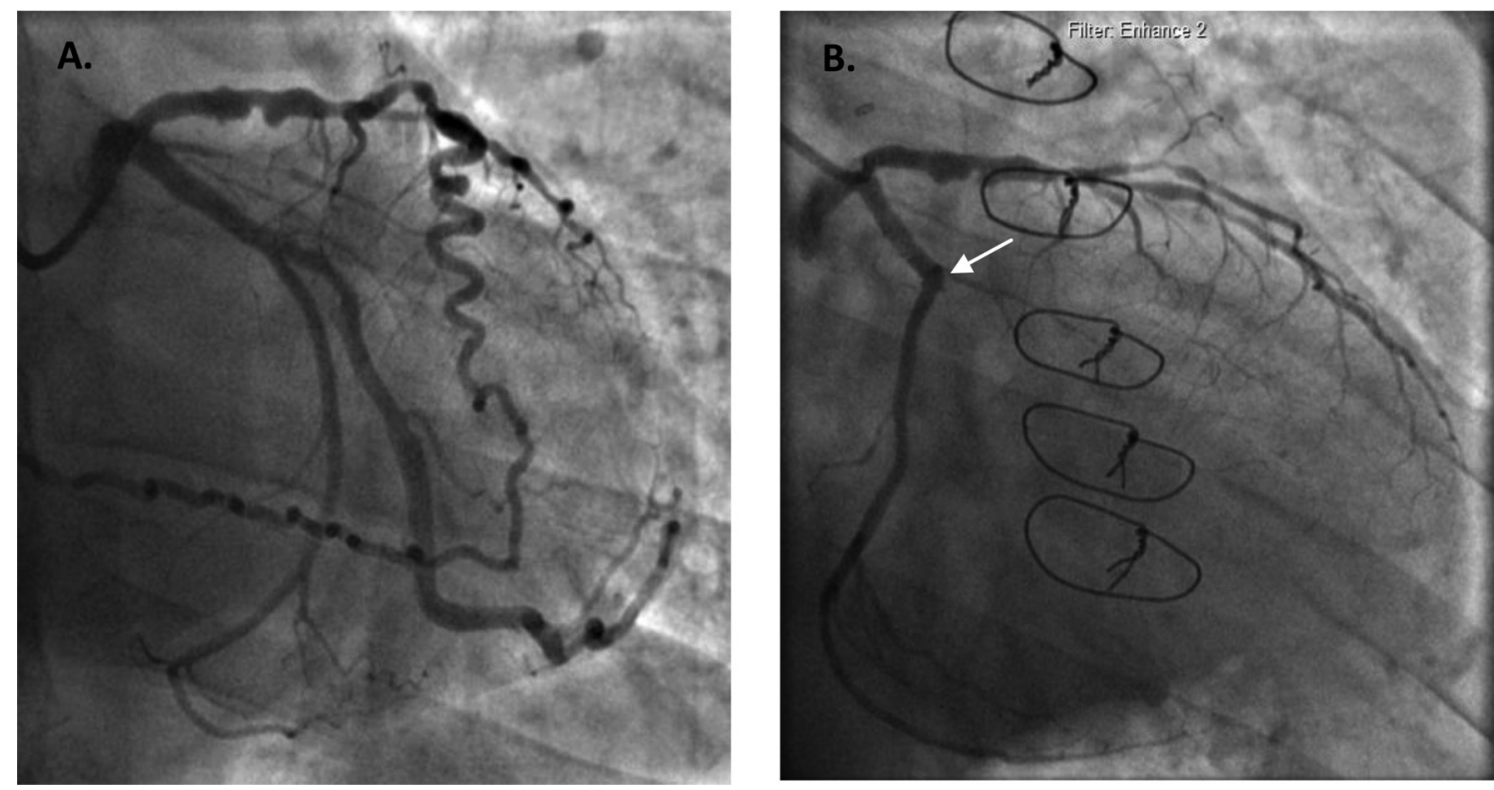

Figure 1 (A) Coronary angiogram in a patient who presented with non-ST elevation myocardial infarction showing severe disease proximally in the LAD coronary artery with collateralisation of an occluded RCA. Coronary artery bypass surgery with grafts to the LAD and RCA produced complete symptomatic relief. (B) Eighteen months later, the patient presented with unstable angina. Coronary angiography confirmed patency of both grafts, but the obtuse marginal branch of the circumflex coronary artery had occluded (arrow) due to rupture of subcritical plaque at its origin. LAD, left anterior descending; RCA, right coronary artery.

registry of $>20000$ patients with stable CAD who underwent non-invasive ischaemia testing (stress ECG, stress echocardiogram or SPECT) also found association between ischaemia and CV endpoints but only for patients with angina (HR 1.75 (95\% CI 1.34 to 2.29)) and patients with silent ischaemia showing no excess risk compared with patients with neither angina nor ischaemia. $^{15}$

\section{Ischaemia and causal pathways of CV risk}

The association of inducible ischaemia with CV endpoints does not confirm its status as a surrogate if it does not lie on the causal pathway for these endpoints. ${ }^{8}$ Evidence questioning a causal role for ischaemia includes the clinical observation that more than half of patients presenting for the first time with myocardial infarction have no prior angina. ${ }^{16} 17$ Similarly, in stable CAD populations including CLARIFY and cohorts attending chest pain clinics, a significant proportion of cardiac events occur in patients without angina or demonstrable ischaemia, no doubt reflecting rupture of non-obstructive plaque that had not been identified by functional testing. ${ }^{15} 18$ These clinical observations suggesting that ischaemia may not be a necessary prerequisite for adverse coronary events are borne out by angiographic studies which show that non-obstructive coronary plaques are as likely to provide a substrate for myocardial infarction as more severely obstructive plaques (figure 1A and B). ${ }^{1920}$ This in turn is consistent with pathophysiological mechanisms of acute coronary syndromes in which it is not the degree of coronary luminal obstruction but the vulnerability of the plaque, defined by factors including cap thickness, lipid pool dimensions and inflammatory infiltrates, that determines the risk of plaque rupture and thrombotic coronary occlusion. ${ }^{21}$ Plaque vulnerability may itself induce endothelial dysfunction and myocardial ischaemia, but this does not put ischaemia on the causal pathway without evidence that its treatment has plaque stabilising effects. ${ }^{22}$ These clinical, angiographic and pathophysiological observations argue against ischaemia lying on the causal pathway for $\mathrm{CV}$ events and question its biological plausibility as a valid surrogate for acute MI (AMI) and coronary death in patients with stable CAD (figure 2).

\section{Diagnostic stress testing and CV outcomes}

A crucial requirement for validation of ischaemia as a surrogate endpoint is that its treatment should cause parallel reduction in the risk of adverse CV outcomes. ${ }^{8-10}$ This would be unlikely if, as argued above, ischaemia does not lie on the causal pathway for these outcomes. Randomised trials of non-invasive ischaemia testing and its contribution to risk reduction in patients with suspected or established CAD are lacking, but indirect evidence from cohort studies tends to confirm that coronary event rates are unaffected by these investigations. In a registry analysis of nearly 250000 patients who had undergone percutaneous coronary intervention (PCI), top quartile hospitals for rates of non-invasive stress testing performed more repeat revascularisation procedures but had almost identical adjusted risk of myocardial infarction and death compared with hospitals in the bottom quartile. ${ }^{23}$ Findings were similar in a study of more than half a million patients with chest pain in 224 US hospitals who underwent cardiac stress imaging. ${ }^{24}$ Again, hospitals with higher imaging rates did not have substantially different rates of therapeutic interventions or lower readmission rates for AMI but were more likely to admit patients and perform angiography. The authors of both studies questioned whether increased testing is a marker for improved quality of post-PCI care or simply increased healthcare utilisation.

\section{Interventions targeted at ischaemia and CV outcomes}

More direct evidence about the validity of inducible ischaemia as a surrogate for CV endpoints comes from observations of treatment effects.

\section{Medical therapy}

For patients with angina, the benefits of targeting ischaemia are well documented and underpin the clinical application of all 


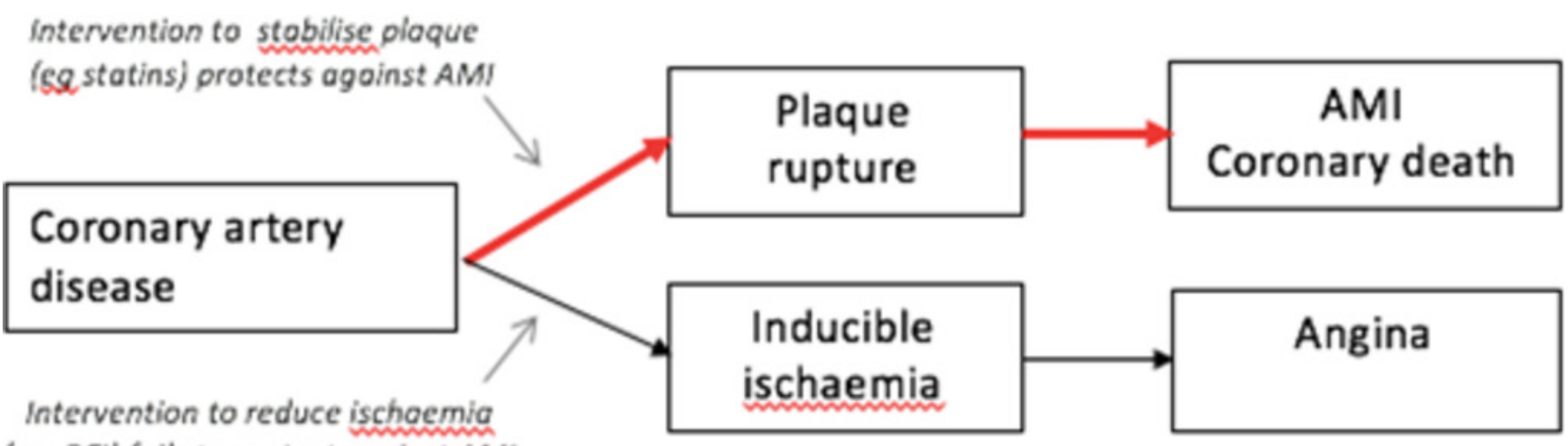
(eq, PCl) foils to protect agoinst AMI

Figure 2 The causal pathway for AMI and coronary death (red arrows). This simplified diagram identifies inducible ischaemia as a consequence of coronary artery disease but shows that if it does not lie on the causal pathway for coronary events, then modification of ischaemia will fail to influence cardiovascular risk. AMI, acute myocardial infarction; $\mathrm{PCl}$, percutaneous coronary intervention.

the commonly used antianginal drugs including nitrates, betablockers, ivabradine and calcium channel blockers. Yet, despite the benefits of these drugs for reducing myocardial ischaemia and correcting symptoms in patients with stable CAD, there is no evidence that they protect against CV events. In The Study Assessing the Morbidity-Mortality Benefits of the If Inhibitor ivabradine in Patients with Coronary Artery Disease, for example, there was no outcome benefit for the group randomised to ivabradine despite significant reduction in angina frequency compared with the placebo group. ${ }^{25}$ In the Reduction of Atherothrombosis for Continued Health (REACH) registry too, the risk of composite $\mathrm{CV}$ events was comparable in propensity matched cohorts stratified by beta-blocker therapy, although the effects of treatment on symptoms or inducible ischaemia were not recorded in this study. ${ }^{26}$

\section{Revascularisation}

PCI can further augment ischaemia reduction in patients receiving medical therapy (MT), but convincing evidence that it protects against $\mathrm{CV}$ events in patients with stable $\mathrm{CAD}$ is lacking. Thus, in the landmark Clinical Outcomes Utilizing Revascularization and Aggressive Drug Evaluation trial, the addition of PCI to optimal MT (OMT) was associated with more effective reduction of ischaemia yet failed to reduce event rates compared with OMT alone. ${ }^{27}$ Patients who exhibited $\geq 5 \%$ reduction in ischaemic myocardium had better outcomes compared with patients with a less pronounced response to treatment, but the difference disappeared in risk-adjusted analysis. ${ }^{28}$ Similarly, in Bypass Angioplasty Revascularization Investigation 2 Diabetes, revascularisation was associated with significantly less ischaemic myocardium at 1 year compared with MT, yet outcomes were similar, and there was no significant difference between the groups in rates of death and major CV events. ${ }^{29}$

Dissociation between ischaemia reduction in response to revascularisation and $\mathrm{CV}$ outcomes in stable $\mathrm{CAD}$ is variably borne out by observational data. In a large study of $>10000$ patients who underwent exercise or adenosine stress myocardial perfusion scintigraphy during the 1990 s, $\sim 7 \%$ underwent revascularisation by PCI or coronary artery bypass grafting (CABG), whereas the remainder continued on medical treatment. ${ }^{30}$ Mortality was higher for revascularisation compared with medical treatment, perhaps reflecting biased selection of sicker patients, and only after multiple comparisons between these treatment strategies for subgroups defined by the extent of ischaemic myocardium could a mortality benefit be demonstrated for revascularisation among patients with $>20 \%$ ischaemic myocardium. This study has been presented as supporting a strategy of revascularisation for reducing ischaemia and protecting against cardiac events despite a substantial overall survival benefit for medically treated patients. Of note was the choice of CABG in the majority of patients with $>20 \%$ ischaemic myocardium which may have contributed to the mortality benefit, less through relief of ischaemia than protection against the consequences of plaque events in the proximal coronary circulation (see below). Similarly, inconclusive was an analysis of nearly 40000 patients with stable CAD from the REACH registry in which the risk of $\mathrm{CV}$ death at 36 months of median follow-up was lower in patients with previous PCI but higher in patients with previous CABG compared with patients managed medically. ${ }^{31}$ Meanwhile, a propensity matched study of MT versus revascularisation in patients with silent ischaemia on myocardial perfusion scintigraphy had found almost identical all-cause mortality in the two groups during follow-up. ${ }^{32}$

Evidence from randomised trials for prognostic benefit of CABG in stable CAD is more robust, and a meta-analysis showed improved survival for CABG compared with medical treatment for patients with left main and multivessel disease, particularly those with left ventricular dysfunction. ${ }^{33}$ The trials included in this meta-analysis were conducted over 40 years ago, but, although relevance to contemporary practice may be questionable, their findings appear to be borne out by the recent Surgical Treatment for IsChemic Heart Failure trial, in which a 10-year follow-up of 1212 patients with ischaemic cardiomyopathy showed reduced rates of death from any cause for patients randomised to CABG compared with medical treatment. ${ }^{34}$ The outcome, however, was independent of inducible ischaemia at baseline, making bypass of vulnerable plaque in the proximal coronary circulation a more likely mechanism of benefit than reduction in ischaemia. ${ }^{35} 36$ PCI offers no protection against plaque events, despite its effectiveness for correcting ischaemia, and this may account for its association with less favourable outcomes and reduced cost-effectiveness compared with CABG in studies that have recruited patients with high ischaemic burden. ${ }^{37-39}$

The treatment data summarised above do not provide a strong case for validation of ischaemia as a surrogate $\mathrm{CV}$ endpoint, but they have been challenged by the Fractional Flow Reserve Versus Angiography for Multivessel Evaluation 2 (FAME-2) trial. ${ }^{40}$ In FAME-2, 888 patients with stable CAD were randomised to 


\section{Table 1 FAME-2}

\begin{tabular}{|c|c|c|c|}
\hline & $\mathrm{PCl}+\mathrm{MT}(\mathrm{n}=447)$ & MT alone $(n=441)$ & \\
\hline & n (\%) & n (\%) & $P$ value \\
\hline MACEs & $45(10.1)$ & $97(22.0)$ & $<0.001$ \\
\hline Death & $12(2.7)$ & $16(3.6)$ & 0.43 \\
\hline $\mathrm{Ml}$ & $28(6.3)$ & $34(7.7)$ & 0.41 \\
\hline Urgent revascularisation & $19(4.3)$ & $76(17.2)$ & $<0.001$ \\
\hline Death or MI & $37(8.3)$ & 46 (10.4) & 0.28 \\
\hline
\end{tabular}

MACEs at a 3-year follow-up in groups randomised to PCl plus MT or to MT alone. FAME-2, Fractional Flow Reserve Versus Angiography for Multivessel Evaluation 2; MACE, major adverse cardiovascular event; $\mathrm{MI}$, myocardial infarction; MT, medical therapy; $\mathrm{PCl}$, percutaneous coronary intervention.

MT or MT plus FFR-guided PCI in which only functionally significant lesions with the potential to cause ischaemia were stented. After 3 years, major adverse cardiac events were significantly less frequent in the PCI group compared with the MT group $(10.1 \%$ vs $22.0 \%$; $<<0.001)$. The outcome advantage for the PCI group was largely driven by a lower rate of urgent revascularisation $(4.3 \%$ vs $17.2 \% ; \mathrm{p}<0.001)$ with no significant difference in rates of death or myocardial infarction (table 1). The extent to which the unblinded treatment allocation in FAME-2 biased the outcome is speculative, but knowledge that the MT group had at least one functionally significant coronary stenosis that had been left unstented might plausibly have reduced thresholds for hospital admission and intervention in patients presenting with recurrent chest pain, resulting in the observed increase in the rate of urgent revascularisation compared with the FFR-guided PCI group. In terms of hard endpoints, however, FAME- 2 was a negative trial and when included in a meta-analysis of five randomised trials investigators concluded that in patients with stable CAD and objectively documented myocardial ischaemia, PCI with MT was not associated with a reduction in death or non-fatal myocardial infarction compared with MT alone. ${ }^{41}$

\section{CLINICAL CONSIDERATIONS}

The data support a unifying hypothesis of ischaemia as a marker of atheroma burden that drives risk through predisposition to plaque events. Interventions that modify ischaemia without affecting plaque stability, therefore, may improve symptoms but are unlikely to have any effect on the risk of myocardial infarction or coronary death (figure 2). This accounts for the failure of antianginal drugs and PCI to reduce CV risk and for the success of statins and anti-inflammatory drugs which target the atherothrombotic process but have no direct anti-ischaemic effects. ${ }^{42}$ Clinically, the evidence favours a symptom-driven management approach in which treatment decisions are based more on chest pain characteristics than the results of functional stress testing. Symptom-driven management recognises that treatment of ischaemia may offer no protection against myocardial infarction or coronary death but is usually effective for relieving symptoms although the Objective Randomised Blinded
Investigation with optimal medical Therapy of Angioplasty in stable angina (ORBITA) trial has cast interesting light on mechanisms contributing to the symptomatic benefit. ${ }^{44}$ This questions the logic of stress testing in asymptomatic patients who may have little to gain prognostically and nothing to gain symptomatically. Stress testing continues to have a role for the diagnosis of coronary disease, yet there is considerable overuse with failure to meet appropriateness criteria in up to $70 \%$ of tests, resulting in increased rates of downstream angiography without influencing the risk of myocardial infarction or coronary death. ${ }^{45} 46$ England's National Institute for Health and Care Excellence has recommended a move away from diagnostic stress testing in favour of anatomical testing with CTCA in patients with suspected angina, but whether its enhanced diagnostic value will be realised in practice awaits confirmation. ${ }^{47}$ Preliminary data are favourable, ${ }^{48}$ and the potential added value of CTCA for identification of vulnerable plaque in patients without inducible ischaemia, if fulfilled, may help identify high risk subgroups invisible to stress testing. ${ }^{49}$ Meanwhile, contemporary healthcare systems face increasing resource constraints with stable CAD contributing importantly to costs. ${ }^{50}$ Addressing the overuse of stress testing represents an important opportunity for reducing costs without adversely affecting patient outcomes.

\section{CONCLUSION}

The balance of available evidence weighs against inducible myocardial ischaemia as a valid surrogate for $\mathrm{CV}$ endpoints and a therapeutic target for risk reduction in patients with stable CAD. It shows that ischaemia associates with adverse CV outcomes but does not lie on the causal pathway, and treatment to reduce ischaemic burden rarely, therefore, protects against myocardial infarction or coronary mortality. In this respect, ischaemia shows similarity with other failed surrogates, such as homocysteine and high-density lipoprotein cholesterol, both of which show association with $\mathrm{CV}$ outcomes that have proved unresponsive to interventions that modify plasma concentrations of these risk factors. ${ }^{5152}$ This contrasts with established surrogates of CV risk, such as low-density lipoprotein cholesterol, treatment of which produces salutary protection against myocardial infarction and coronary death (table 2). ${ }^{42}$

Consistent though the data are in portraying inducible myocardial ischaemia as a failed surrogate for CV endpoints, they cannot be considered confirmatory. The Hachamovitch study remains influential based on its finding of improved outcomes with revascularisation (predominantly CABG) in a severely ischaemic subgroup, ${ }^{11}$ and FAME-2 concluded that FFR-guided coronary stenting plus best available MT was superior to MT alone for reducing rates of composite CV outcomes, even though rates of death and myocardial infarction were unaffected. ${ }^{40}$ Residual uncertainty about the role of a symptom-driven approach in the management of patients with stable CAD may be resolved by the ongoing International Study of Comparative Health Effectiveness with Medical and Invasive

Table 2 Validation criteria for four CV biomarkers

\begin{tabular}{|c|c|c|c|c|}
\hline Validation criteria & $\begin{array}{l}\text { Inducible } \\
\text { ischaemia }\end{array}$ & LDL cholesterol & HDL cholesterol & Homocysteine \\
\hline 1. Prognostic value: does biomarker correlate with adverse $\mathrm{CV}$ outcomes? & +++ & +++ & +++ & ++ \\
\hline 2. Biological plausibility: is biomarker on the causal pathway for adverse CV outcomes? & $+l-$ & +++ & + & - \\
\hline
\end{tabular}


Approaches in which recruitment of 5000-6000 patients with preserved left ventricular function (ejection fraction $\geq 35 \%$ ) and at least moderate ischaemia on non-invasive testing is almost complete. ${ }^{53}$ These patients are being randomised to an invasive or conservative management strategy with follow-up for all-cause and CV mortality. Whether the invasive approach delivers improved CV outcomes as a consequence of more effective reductions in ischaemic burden is an important question that will further inform debate about management strategies in patients with stable CAD.

Contributors AR performed the initial literature review, wrote the first draft of the manuscript and critically reviewed all subsequent drafts. AT edited the first draft and wrote all subsequent drafts. RAA was responsible for some of the original thought behind this review and edited and critically reviewed the final drafts of the manuscript. AM edited and critically reviewed the final drafts of the manuscript.

Funding The authors have not declared a specific grant for this research from any funding agency in the public, commercial or not-for-profit sectors.

Competing interests None declared.

Patient consent Obtained.

Provenance and peer review Not commissioned; externally peer reviewed.

Open access This is an open access article distributed in accordance with the Creative Commons Attribution Non Commercial (CC BY-NC 4.0) license, which permits others to distribute, remix, adapt, build upon this work non-commercially, and license their derivative works on different terms, provided the original work is properly cited and the use is non-commercial. See: http://creativecommons.org/ licenses/by-nc/4.0/

(c) Article author(s) (or their employer(s) unless otherwise stated in the text of the article) 2018. All rights reserved. No commercial use is permitted unless otherwise expressly granted.

\section{REFERENCES}

1 Deedwania PC, Carbajal EV. Silent myocardial ischemia. A clinical perspective. Arch Intern Med 1991;151:2373-82.

2 Bugiardini R, Cenko E. Persisting chest pain in nonobstructive coronary artery disease Eur Heart J Qual Care Clin Outcomes 2016;2:69-71.

3 Pijls NH, De Bruyne B, Peels K, et al. Measurement of fractional flow reserve to assess the functional severity of coronary-artery stenoses. N Engl J Med 1996;334:1703-8.

4 Xu B, Tu S, Qiao S, et al. Diagnostic Accuracy of Angiography-Based Quantitative Flow Ratio Measurements for Online Assessment of Coronary Stenosis. J Am Coll Cardiol 2017;70:3077-87.

5 NICE Medical technologies guidance [MTG32]. HeartFlow FFRCT for estimating fractional flow reserve from coronary CT angiography. 2017 https://www.nice.org.uk/ guidance/mtg32.

6 Montalescot G, Sechtem U, Achenbach S, et al. 2013 ESC guidelines on the management of stable coronary artery disease: the Task Force on the management of stable coronary artery disease of the European Society of Cardiology. Eur Heart $J$ 2013:34:2949-3003.

7 Fihn SD, Gardin JM, Abrams J, et al. 2012 ACCF/AHA/ACP/AATS/PCNA/SCAl/STS Guideline for the diagnosis and management of patients with stable ischemic heart disease: a report of the American College of Cardiology Foundation/American Heart Association Task Force on Practice Guidelines, and the American College of Physicians, American Association for Thoracic Surgery, Preventive Cardiovascular Nurses Association, Society for Cardiovascular Angiography and Interventions, and Society of Thoracic Surgeons. J Am Coll Cardiol 2012;60:e44-e164.

8 Bikdeli B, Punnanithinont N, Akram Y, et al. Two decades of cardiovascular trials with primary surrogate endpoints: 1990-2011. J Am Heart Assoc 2017;6:e005285.

9 Fleming TR, Powers JH. Biomarkers and surrogate endpoints in clinical trials. Stat Med 2012:31:2973-84.

10 Weintraub WS, Lüscher TF, Pocock S. The perils of surrogate endpoints. Eur Heart J 2015:36:2212-8.

11 Hachamovitch R, Berman DS, Shaw LJ, et al. Incremental prognostic value of myocardial perfusion single photon emission computed tomography for the prediction of cardiac death: differential stratification for risk of cardiac death and myocardial infarction. Circulation 1998:97:535-43.

12 Kral BG, Becker DM, Vaidya D, et al. Severity of inducible myocardial ischemia predicts incident acute coronary syndromes in asymptomatic individuals with a family history of premature coronary artery disease. J Nucl Cardiol 2012;19:28-36.

13 Lipinski MJ, McVey CM, Berger JS, et al. Prognostic value of stress cardiac magnetic resonance imaging in patients with known or suspected coronary artery disease: a systematic review and meta-analysis. J Am Coll Cardiol 2013;62:826-38.
14 Wang EY, Dixson J, Schiller NB, et al. Causes and predictors of death in patients with coronary heart disease (from the heart and soul study). Am J Cardiol 2017;119:27-34.

15 Steg PG, Greenlaw N, Tendera M, et al. Prevalence of anginal symptoms and myocardial ischemia and their effect on clinical outcomes in outpatients with stable coronary artery disease: data from the International Observational CLARIFY Registry. JAMA Intern Med 2014;174:1651-9.

16 Herlitz J, Karlson BW, Richter A, et al. Occurrence of angina pectoris prior to acute myocardial infarction and its relation to prognosis. Eur Heart J 1993;14:484-91.

17 Jiménez-Navarro MF, Muñoz-García A, Ramirez-Marrero MA, et al. Preinfarction angina prior to first myocardial infarction does not influence long-term prognosis: a retrospective study with subgroup analysis in elderly and diabetic patients. Clin Cardiol 2009:32:E61-E64.

18 Sekhri N, Feder GS, Junghans $C$, et al. How effective are rapid access chest pain clinics? Prognosis of incident angina and non-cardiac chest pain in 8762 consecutive patients. Heart 2007;93:458-63.

19 Shah PK. Mechanisms of plaque vulnerability and rupture. J Am Coll Cardiol 2003:41:S15-S22.

20 Falk E, Shah PK, Fuster V, et al. Coronary plaque disruption. Circulation 1995;92:657-71

21 Falk E, Nakano M, Bentzon JF, et al. Update on acute coronary syndromes: the pathologists' view. Eur Heart J 2013;34:719-28.

22 Ahmadi A, Stone GW, Leipsic J, et al. Association of coronary stenosis and plaque morphology with fractional flow reserve and outcomes. JAMA Cardiol 2016;1:350-7.

23 Shah BR, McCoy LA, Federspiel JJ, et al. Use of stress testing and diagnostic catheterization after coronary stenting: association of site-level patterns with patient characteristics and outcomes in 247,052 Medicare beneficiaries. J Am Coll Cardiol 2013:62:439-46.

24 Safavi KC, Li SX, Dharmarajan K, et al. Hospital variation in the use of noninvasive cardiac imaging and its association with downstream testing, interventions, and outcomes. JAMA Intern Med 2014;174:546-53.

25 Fox K, Ford I, Steg PG, et al. Ivabradine in stable coronary artery disease without clinical heart failure. N Engl J Med 2014;371:1091-9.

26 Bangalore S, Steg G, Deedwania P, et al. $\beta$-Blocker use and clinical outcomes in stable outpatients with and without coronary artery disease. JAMA 2012;308:1340-9.

27 Boden WE, O'Rourke RA, Teo KK, et al. Optimal medical therapy with or without PCI for stable coronary disease. N Engl J Med 2007;356:1503-16.

28 Shaw LJ, Berman DS, Maron DJ, et al. Optimal medical therapy with or without percutaneous coronary intervention to reduce ischemic burden: results from the Clinical Outcomes Utilizing Revascularization and Aggressive Drug Evaluation (COURAGE) trial nuclear substudy. Circulation 2008;117:1283-91.

29 Shaw LJ, Cerqueira MD, Brooks MM, et al. Impact of left ventricular function and the extent of ischemia and scar by stress myocardial perfusion imaging on prognosis and therapeutic risk reduction in diabetic patients with coronary artery disease: results from the Bypass Angioplasty Revascularization Investigation 2 Diabetes (BARI 2D) trial. J Nucl Cardiol 2012;19:658-69.

30 Hachamovitch R, Hayes SW, Friedman JD, et al. Comparison of the short-term survival benefit associated with revascularization compared with medical therapy in patients with no prior coronary artery disease undergoing stress myocardial perfusion single photon emission computed tomography. Circulation 2003;107:2900-7.

31 Elbez Y, Cheong AP, Fassa AA, et al. Clinical outcomes in patients with stable coronary artery disease with vs. without a history of myocardial revascularization. Eur Heart J Qual Care Clin Outcomes 2016:2:23-32.

32 Aldweib N, Negishi K, Hachamovitch R, et al. Impact of repeat myocardial revascularization on outcome in patients with silent ischemia after previous revascularization. J Am Coll Cardiol 2013;61:1616-23.

33 Yusuf S, Zucker D, Peduzzi P, et al. Effect of coronary artery bypass graft surgery on survival: overview of 10-year results from randomised trials by the Coronary Artery Bypass Graft Surgery Trialists Collaboration. Lancet 1994;344:563-70.

34 Velazquez EJ, Lee KL, Jones RH, et al. Coronary-Artery Bypass Surgery in Patients with Ischemic Cardiomyopathy. N Engl J Med 2016:374:1511-20.

35 Panza JA, Holly TA, Asch FM, et al. Inducible myocardial ischemia and outcomes in patients with coronary artery disease and left ventricular dysfunction. J Am Coll Cardiol 2013:61:1860-70

36 de Belder MA. Prognostic impact of percutaneous coronary intervention in stable coronary disease. Eur Heart I Qual Care Clin Outcomes 2016:2:1-3.

37 Farkouh ME, Domanski M, Sleeper LA, et al. Strategies for multivessel revascularization in patients with diabetes. N Engl J Med 2012;367:2375-84

38 Serruys PW, Morice MC, Kappetein AP, et al. Percutaneous coronary intervention versus coronary-artery bypass grafting for severe coronary artery disease. $N$ Engl $\mathrm{f}$ Med 2009;360:961-72.

39 Ariyaratne TV, Yap CH, Ademi Z, et al. A systematic review of cost-effectiveness of percutaneous coronary intervention vs. surgery for the treatment of multivessel coronary artery disease in the drug-eluting stent era. Eur Heart I Qual Care Clin Outcomes 2016:2:261-70.

40 Fearon WF, Nishi T, De Bruyne B, et al. Clinical Outcomes and Cost-Effectiveness of Fractional Flow Reserve-Guided Percutaneous Coronary Intervention in Patients With Stable Coronary Artery Disease: Three-Year Follow-Up of the FAME 2 Trial 
(Fractional Flow Reserve Versus Angiography for Multivessel Evaluation). Circulation 2018;137:480-7.

41 Stergiopoulos K, Boden WE, Hartigan P, et al. Percutaneous coronary intervention outcomes in patients with stable obstructive coronary artery disease and myocardial ischemia: a collaborative meta-analysis of contemporary randomized clinical trials. JAMA Intern Med 2014;174:232-40.

42. Baigent C, Keech A, Kearney PM, et al. Efficacy and safety of cholesterol-lowering treatment: prospective meta-analysis of data from 90,056 participants in 14 randomised trials of statins. Lancet 2005;366:1267-78.

43 Ridker PM, Everett BM, Thuren T, et al. Antiinflammatory therapy with canakinumab for atherosclerotic disease. N Engl J Med 2017;377:1119-31.

44 Al-Lamee R, Thompson D, Dehbi HM, et al. Percutaneous coronary intervention in stable angina (ORBITA): a double-blind, randomised controlled trial. Lancet 2018;391:31-40.

45 Rao VM, Levin DC. The overuse of diagnostic imaging and the Choosing Wisely initiative. Ann Intern Med 2012;157:574-6.

46 Ladapo JA, Blecker S, Douglas PS. Physician decision making and trends in the use of cardiac stress testing in the United States: an analysis of repeated cross-sectional data. Ann Intern Med 2014;161:482-90.

47 Timmis A, Roobottom CA. National institute for health and care excellence updates the stable chest pain guideline with radical changes to the diagnostic paradigm. Heart 2017;103:982-6.
48 Adamson PD, Hunter A, Williams MC, et al. Diagnostic and prognostic benefits of computed tomography coronary angiography using the 2016 National Institute for Health and Care Excellence guidance within a randomised trial. Heart 2018;104:207-14.

49 Otsuka K, Fukuda S, Tanaka A, et al. Prognosis of vulnerable plaque on computed tomographic coronary angiography with normal myocardial perfusion image. Eur Heart J Cardiovasc Imaging 2014;15:332-40.

50 Walker S, Asaria M, Manca A, et al. Long-term healthcare use and costs in patients with stable coronary artery disease: a population-based cohort using linked health records (CALIBER). Eur Heart I Qual Care Clin Outcomes 2016;2:125-40.

51 Vermeulen EG, Stehouwer CD, Twisk JW, et al. Effect of homocysteine-lowering treatment with folic acid plus vitamin $\mathrm{B} 6$ on progression of subclinical atherosclerosis: a randomised, placebo-controlled trial. Lancet 2000;355:517-22.

52 Keene D, Price C, Shun-Shin MJ, et al. Effect on cardiovascular risk of high density lipoprotein targeted drug treatments niacin, fibrates, and CETP inhibitors: meta-analysis of randomised controlled trials including 117,411 patients. BMJ 2014;349:94379.

53 Shaw LJ, Phillips LM, Picard MH, et al. An Update on the ISCHEMIA Trial. 2017. http:// www.acc.org/latest-in-cardiology/articles/2017/07/25/14/30/an-update-on-theischemia-trial 